\title{
Barium Diphenylamine-4-Sulfonate (BDPA) Ion-Ion Interactions and Solvation Volumes in Acetonitrile-Water Mixed Solvents
}

\author{
Elsayed T. Helmy ${ }^{1,2, ~ *, ~ E s a m ~ A . ~ G o m a a ~}{ }^{2}$, Elsayed M. Abou Eleef ${ }^{3}$ \\ ${ }^{1}$ Marine Pollution Research Lab., National Institute of Oceanography and Fisheries, Ministry of Scientific Research, Alexandria, Egypt \\ ${ }^{2}$ Chemistry Department, Faculty of Science, Mansoura University, Mansoura, Egypt \\ ${ }^{3}$ Basic Science Department, Delta Higher Institute for Engineering \& Technology, Dakhlia, Mansoura, Egypt
}

Email address:

stalaat41@yahoo.com (E. T. Helmy)

${ }^{*}$ Corresponding author

\section{To cite this article:}

Elsayed T. Helmy, Esam A. Gomaa, Elsayed M. Abou Eleef. Barium Diphenylamine-4-Sulfonate (BDPA) Ion-Ion Interactions and Solvation Volumes in Acetonitrile-Water Mixed Solvents. Modern Chemistry. Vol. 5, No. 6, 2017, pp. 101-105. doi: 10.11648/j.mc.20170506.13

Received: November 7, 2017; Accepted: November 20, 2017; Published: January 2, 2018

\begin{abstract}
The aim of this work is to calculate ion-ion interaction, density of organic-aqueous mixtures of Acetonitrile-water $\left(A N-H_{2} \mathrm{O}\right)$, density of saturated solutions of BDPA, salvation volumes (Van der Waals volume $\mathrm{V}_{\mathrm{W}}$, molar volume $\mathrm{V}_{\mathrm{M}}$ and electrostriction volume $V_{e}$ ) and solvated radii $\left(r_{o}\right)$ from solubility experiments. It was found that values of the $\log$ activity coefficient $\left(\gamma_{+}\right)$of BDPA in $\left(\mathrm{AN}-\mathrm{H}_{2} \mathrm{O}\right)$ mixture were decreases by increasing in the content of the organic solvent used. The values of the $\log \gamma_{+}$found to decrease with the increase in temperature. The densities and the molar volumes of the saturated solutions of BDPA decrease by increasing ratio of $\mathrm{AN}$ and also increases by increasing in temperature. All the electrostriction volumes calculated for BDPA having negative values. The electrostriction volumes increase in negativity on increasing the percentages of the organic solvent. The solvated radii of BDPA are increased as the organic solvent content increase and as the temperature increase.
\end{abstract}

Keywords: Ion-Ion Interactions, Barium Diphenylamine 4-Sulfonate, Acetonitrile, Solubility, Solvation Volumes

\section{Introduction}

Low aqueous solubility and reduced dissolution rates are a common property of many new drug candidates, and these properties create a number of challenges during drug discovery and development. An understanding of the determinants of solubility and dissolution provides a framework from which approaches to enhance solubilization may be developed. In subsequent sections of this review, we first address the complexities of working with poorly watersoluble drugs in vitro and subsequently summarize the approaches that can be taken to assist in the development of both parenteral and oral formulations. The main body of the review follows and provides a detailed account of the technological approaches that can be taken to support the development of effective formulations for poorly watersoluble drugs. Comment is made as to the many different approaches that might be taken during lead optimization and preclinical development and also those strategies that are also appropriate for extension into clinical development and ultimately to the market. To constrain the scope of this review, synthetic medicinal chemistry approaches to solubility manipulation are not addressed and the discussion is limited to approaches that do not result in the generation of a fundamentally new chemical entity. For more information on approaches to solubility manipulation via structural modification [1-5].

A further application of the solubility-permeability relationship to oral drug absorption is the Biopharmaceutics Classification System (BCS) originally developed. [6] with subsequent variations [7-9]. The principles of the BCS are well described elsewhere [10-12], but in brief, the BCS 
allows classification of drug molecules as a function of their solubility and permeability properties. A lot of published data [13-20] for BDPA and other substances that shows that they are very important materials for different fields.

\section{Materials and Methods}

High grade of Barium diphenylamine sulfonate (BDH), ethanol were supplied from Merck, double distilled water that have measured specific conductance $2 \times 10^{-7} \mathrm{~S} \mathrm{~cm}^{-1}$.

The mixed solvents, $\left(\mathrm{AN}+\mathrm{H}_{2} \mathrm{O}\right.$ by percent values of $\mathrm{AN}$ $=0,20,40,60,80$ and $100 \%$ by volume), were prepared from double distilled water and fairly pure AN. Then, saturated solutions of BDPA were prepared by dissolving different amounts in closed test tubes containing different $\left(\mathrm{AN}+\mathrm{H}_{2} \mathrm{O}\right)$ mixtures. The tubes were placed in a shaking thermostat (Model Gel) for a period of four days till equilibrium reached. The solubility, $\mathrm{S}$ (mole/Kg.solvent), of BDPA in the mixed solvent at different temperature was determined gravimetrically by the solvent evaporating method. All the solubility experiments were repeated at least three times and the results were averaged.

\section{Results and Discussion}

\subsection{Ion-Ion Interaction Calculations}

For an ionic compound, with the formula $\mathrm{AB}_{2}$, we may consider the following equilibrium in its saturated solution at a given constant temperature.

$$
\mathrm{AB}_{2}(\mathrm{~s}) \leftrightarrow \mathrm{A}_{(\mathrm{aq})}^{2+}+2 \mathrm{~B}_{(\mathrm{aq})}^{-}, \mathrm{K}_{\mathrm{sp}(\mathrm{th})}=\mathrm{a}_{+} . \mathrm{a}_{-}
$$

Where $K_{\text {sp(th) }}$ denotes the thermodynamic solubility product constant and $\mathrm{a}_{+}$and $\mathrm{a}_{-}$refer to activity of $\mathrm{A}^{2+}$ and $\mathrm{B}^{-}$ in the solution, respectively. If the solubility of $\mathrm{AB}_{2}$ is very low, it may replace the activity of each ion by its concentration, so,

$$
\mathrm{K}_{\mathrm{sp}(\mathrm{th})}=4 \mathrm{~s}_{\mathrm{o}}{ }^{3}
$$

Where $\mathrm{s}_{\mathrm{o}}$ represents the molarity of $\mathrm{BA}_{2}$ in the very dilute solution. The electrostatic interaction becomes very small and the ion association phenomenon may be negligible (the activity coefficient $\gamma_{ \pm} \sim 1$, [13-16].

Ion-ion interaction is a function of the mean activity coefficient $\left(\gamma_{ \pm}\right)$of the ions. There are several theoreticallybased expressions that can be used to estimate the activity coefficients. At very low concentration, the electrostatic interaction becomes very small and the ion association phenomenon may be negligible (the activity coefficient $\gamma_{ \pm} \sim 1$ ) [21-23].

At low concentration, the activity coefficient may be determined by using the Debye- Hückel limiting law:

$$
\log \gamma_{ \pm}=-Z_{+} Z_{-} A \sqrt{\mathrm{I}} \text { applicable for } \mathrm{I}<10^{-2} \mathrm{M}
$$

Where $\mathrm{Z}_{+}$and $\mathrm{Z}_{-}$are the charges of ions in solutions, $A=$
$1.823 \times 10^{6}(\varepsilon . T)^{-3 / 2}$, the ionic strength, I, defined as, $I=\frac{1}{2} \sum_{i} m_{i} z_{i}^{2} \quad\left(\mathrm{z}_{\mathrm{i}}\right.$ is the charge on ion $\mathrm{i}$, and $\mathrm{m}_{\mathrm{i}}$ is the molality of ion i) and the ionic strength, I emphasizes the charges of ions because the charge numbers occur as their squares.

At relatively high concentration, the electrostatic interaction becomes very large [24-25]. The activity coefficient may be determined using the extend DebyeHückel law:

$$
\log \gamma_{ \pm}=-\frac{Z_{+} Z_{-} A \sqrt{\mathrm{I}}}{I+B r^{o} \sqrt{\mathrm{I}}} \text { for } \mathrm{I}<10^{-1} \mathrm{M}
$$

Where $B=50.29 \times 10^{8}(\varepsilon T)^{-1 / 2}$, and $\mathrm{r}^{\circ}$ is the solvated radius.

At high concentrations, activity coefficients of electrolyte solutions can be determined by using the Davies equation ${ }^{[21]}$ which is an empirical extension of Debye-Hückel theory. The final form of the equation gives the mean molal activity coefficient, $\gamma_{ \pm}$, of an electrolyte which dissociates into ions having charges $z_{+}$and $z_{\text {- }}$ as a function of ionic strength, $I$.

$$
\log \gamma_{ \pm}=-Z_{+} Z_{-} A\left(\frac{\sqrt{\mathrm{I}}}{I+\sqrt{\mathrm{I}}}-0.3 I\right)
$$

The second term, $0.3 \mathrm{I}$, goes to zero as the ionic strength goes to zero, so the equation reduces to the Debye-Hückel equation at low concentration. However, as concentration increases, the second term becomes increasingly important, so the Davies equation can be used for solutions too concentrated to allow the use of the Debye-Hückel equation.

The results of the ionic strength for BDPA in $\left(\mathrm{AN}-\mathrm{H}_{2} \mathrm{O}\right)$ mixture are illustrated in Table 1 . The values of the $\log \gamma_{ \pm}$

\begin{tabular}{|c|c|c|c|c|c|}
\hline \multirow{2}{*}{ AN vol.\% } & \multirow{2}{*}{$\mathbf{X}_{\mathrm{s}}$} & \multicolumn{4}{|l|}{ I } \\
\hline & & $293.15 \mathrm{~K}$ & $298.15 \mathrm{~K}$ & $303.15 \mathrm{~K}$ & $308.15 \mathrm{~K}$ \\
\hline 0 & 0 & 0.604 & 0.6369 & 0.6704 & 0.6884 \\
\hline 20 & 0.0788 & 0.0479 & 0.0564 & 0.0647 & 0.077 \\
\hline 40 & 0.1857 & 0.0412 & 0.0454 & 0.0537 & 0.0705 \\
\hline 60 & 0.3391 & 0.0383 & 0.0428 & 0.0515 & 0.0689 \\
\hline 80 & 0.577 & 0.0315 & 0.0363 & 0.0454 & 0.0684 \\
\hline 100 & 1 & 0.0304 & 0.0355 & 0.0407 & 0.0459 \\
\hline
\end{tabular}
for BDPA in $\left(\mathrm{AN}-\mathrm{H}_{2} \mathrm{O}\right)$ mixture are illustrated in Table 2 are shown in Figure 1.

Table 1. Ionic strength (I) for BDPA in $\left(\mathrm{AN}-\mathrm{H}_{2} \mathrm{O}\right)$ mixed solvents at different temperatures.

Table 2. Log activity coefficient (log $\left.\gamma_{ \pm}\right)$for BDPA in $\left(\mathrm{AN}-\mathrm{H}_{2} \mathrm{O}\right)$ mixed solvents at different temperatures.

\begin{tabular}{llllll}
\hline \multirow{2}{*}{ AN vol.\% } & \multirow{2}{*}{$\mathbf{X}_{\mathbf{s}}$} & \multicolumn{1}{l}{$\log \gamma_{ \pm}$} & & & \\
\cline { 3 - 6 } & & $\mathbf{2 9 3 . 1 5} \mathbf{K}$ & $\mathbf{2 9 8 . 1 5} \mathbf{~ K}$ & $\mathbf{3 0 3 . 1 5 ~ K}$ & $\mathbf{3 0 8 . 1 5 ~ K}$ \\
\hline 0 & 0 & 0.551119 & 0.5513 & 0.551646 & 0.5494 \\
20 & 0.0788 & 0.663206 & 0.6443 & 0.626893 & 0.6052 \\
40 & 0.1857 & 0.655435 & 0.6403 & 0.61861 & 0.5857 \\
60 & 0.3391 & 0.623203 & 0.6046 & 0.581267 & 0.5424 \\
80 & 0.577 & 0.566068 & 0.544 & 0.520782 & 0.4557 \\
100 & 1 & 0.364617 & 0.3413 & 0.31364 & 0.2917 \\
\hline
\end{tabular}




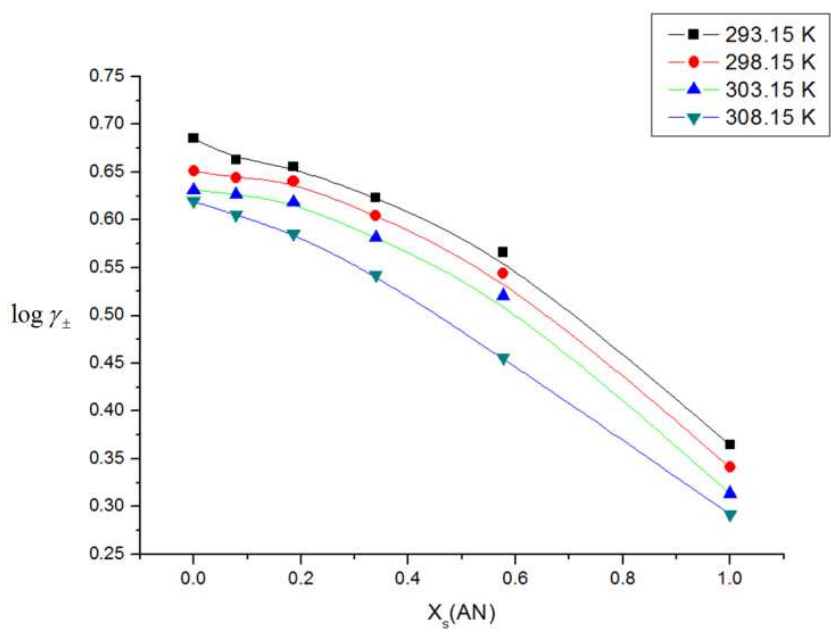

Figure 1. Relation between the activity coefficient $\left(\log \gamma_{ \pm}\right)$of BDPA and the mole fraction of $A N\left(X_{s}\right)$ in mixed solvents at different temperatures.

It was found that values of the $\log \gamma_{ \pm}$of BDPA were decreases by increasing in the content of the organic solvent used (AN) due to decrease in its solubility which lead to a decrease of the electrostatic interaction becomes and the ion association. The values of the $\log \gamma_{ \pm}$found to decrease with the increase in temperature due to a decrease of the electrostatic interaction becomes and the ion association.

\subsection{Density Measurements}

\subsubsection{Density of the Saturated Solutions}

Table 3 show the density of the saturated solutions of BDPA in $\left(\mathrm{AN}-\mathrm{H}_{2} \mathrm{O}\right)$ mixtures, at different temperatures $(293.15,298.15,303.15$ and $308.15 \mathrm{~K})$. It is obvious that the densities of the saturated solutions of BDPA decrease by increasing ratio of $\mathrm{AN}$ and also increases by increasing in temperature.

Table 3. Density (d) of saturated solution of BDPA in $\left(\mathrm{AN}-\mathrm{H}_{2} \mathrm{O}\right)$ mixed solvents at different temperatures.

\begin{tabular}{lllll}
\hline \multirow{2}{*}{ AN vol.\% } & (d) & & & \\
\cline { 2 - 5 } & $\mathbf{2 9 3 . 1 5} \mathbf{K}$ & $\mathbf{2 9 8 . 1 5} \mathbf{~ K}$ & $\mathbf{3 0 3 . 1 5} \mathbf{~ K}$ & $\mathbf{3 0 8 . 1 5} \mathbf{~ K}$ \\
\hline 0 & 1.53 & 1.61 & 1.734 & 1.835 \\
20 & 0.966 & 0.974 & 0.981 & 0.994 \\
40 & 0.943 & 0.95 & 0.954 & 0.963 \\
60 & 0.887 & 0.897 & 0.9 & 0.912 \\
80 & 0.846 & 0.853 & 0.859 & 0.863 \\
100 & 0.776 & 0.781 & 0.793 & 0.81 \\
\hline
\end{tabular}

\subsubsection{Calculation of the Solvation Volumes and the Solvated Radii}

From density and molal solubility measurements of the saturated solutions of BDPA in $\left(\mathrm{AN}-\mathrm{H}_{2} \mathrm{O}\right)$ mixtures, the molar volumes (V) [24-25] are calculated, at different temperatures $(293.15,298.15,303.15$ and $308.15 \mathrm{~K}$ ) according to equation (6)

$$
V=\frac{M}{d}
$$

Where $\mathrm{M}$ is the molecular weight of BDPA, $d$ is the density of the solution;. The molecular weights of the binary solvents are calculated using equation (7)

$$
M=X_{S(1)\left(\mathrm{H}_{2} \mathrm{O}\right)} \cdot \mathrm{M}_{\left(\mathrm{H}_{2} \mathrm{O}\right)}+X_{S(2)(O . S)} \cdot M_{(O . S)}
$$

Where $M_{\left(\mathrm{H}_{2} \mathrm{O}\right)}$ and $M_{(\mathrm{OS})}$ are the molecular weights of water and organic $X_{S(1)\left(\mathrm{H}_{2} \mathrm{O}\right)} X_{(\mathrm{OS})}$ solvent, respectively, and are the mole fractions of water and the organic solvents used by are calculated by applying equation (8):

$$
X_{S(1)} \text { by wt. }=\frac{\frac{\mathrm{Vol} . \%(1) \times \mathrm{d}(1)}{\mathrm{M}_{1}}}{\frac{\mathrm{Vol} . \%(1) \mathrm{X} \mathrm{d}(1)}{\mathrm{M}_{1}}+\frac{\text { Vol.\% (2) } \mathrm{X} \mathrm{d} \mathrm{(2)}}{\mathrm{M}_{2}}}
$$

Where $d_{(1)}$ and $d_{(2)}$ are the densities of the organic solvent and water, respectively, and $\mathrm{M}_{1}$ and $\mathrm{M}_{2}$ are the molecular weights of the organic solvent and water respectively, vol.\% (1) and vol.\% (2) are the volume percentages of the organic solvent and water, respectively.

The packing density (i.e., the relation between the Van der Waals volumes and the partial molar volumes) of relatively large molecules (more than 40) is found to be constant. Therefore, it is possible to calculate the Van der Waals volumes $\left(\mathrm{V}_{\mathrm{w}}\right)$ of BDPA in $\left(\mathrm{AN}-\mathrm{H}_{2} \mathrm{O}\right)$ salt mixtures in at different temperatures $(293.15,298.15,303.15$ and $308.15 \mathrm{~K}$ ) by applying equation ( 9 ).

$$
\text { Packing density }(\mathrm{P})==\frac{V_{w}}{V} \quad 0.661 \pm 0.017
$$

Where $\mathrm{V}_{\mathrm{w}}$ and $\mathrm{V}$ are the Van der Waals and partial molar volumes, respectively.

The electrostriction volume $\left(\mathrm{V}_{\mathrm{e}}\right)$ [25-27] which is the volume of the solute compressed by the solvent is calculated by using equation (10).

$$
\mathrm{Ve}=\mathrm{Vw}-\mathrm{V}
$$

The values of $V, V_{w}$ and $V_{e}$ of BDPA in $\left(\mathrm{AN}-\mathrm{H}_{2} \mathrm{O}\right)$ mixtures; at different temperatures $(293.15,298.15,303.15$ and $308.15 \mathrm{~K}$ ) are listed in Tables 4-5 respectively.

In comparing the data of solvation, it is was observed that the values of the molar volume of ethanol mixtures with water are increased by increasing the organic solvents content in the mixtures due to the increase in the volume of organic solvent compared to water.

All the electrostriction volumes calculated for BDPA in $\left(\mathrm{AN}-\mathrm{H}_{2} \mathrm{O}\right)$ mixtures having negative values. The electrostriction volumes increase in negativity on increasing the percentages of the organic solvent, indicating the more work (energy) is done by the solvent on the solvation sheaths of the salts.

The solvated radii of the organic-aqueous mixtures; (AN$\left.\mathrm{H}_{2} \mathrm{O}\right)$ at different temperatures $(293.15,298.15,303.15$ and $308.15 \mathrm{~K}$ were calculated using equation (11) by considering the spherical form of the solvated molecules [25-27].

$$
V=\frac{1}{6} \Pi N \sigma^{3}
$$


Where $V$ is the molar volume calculated from the densities as described before and $\sigma$ is the solvated diameter. The solvated radii of BDPA in mixtures were calculated by adding the crystal radius of the salt to the radii of solvent in BDPA $\left(\mathrm{AN}-\mathrm{H}_{2} \mathrm{O}\right)$ mixtures at different temperatures (293.15,
298.15, 303.15 and $308.15 \mathrm{~K})$.

The calculated values of the solvated radii of BDPA (AN$\mathrm{H}_{2} \mathrm{O}$ ) mixtures at different temperatures $(293.15,298.15$, 303.15 and $308.15 \mathrm{~K}$ ) as well as the solutions of BDPA in $\left(\mathrm{AN}-\mathrm{H}_{2} \mathrm{O}\right)$ mixtures are listed in tables 4 and 5.

Table 4. Molar volume (V), Van der Waals volume $\left(V_{w}\right)$, electrostriction volume $\left(V_{e}\right)$ and Solvated radii $\left(r_{o}\right)$ of $B D P A$ in different $\left(A N-H_{2} O\right)$ mixed solvents at $293.15 \mathrm{~K}$ and $298.15 \mathrm{~K}$. $\left(\mathrm{Cm}^{3} . \mathrm{mol}^{-1}\right)$.

\begin{tabular}{|c|c|c|c|c|c|c|c|c|}
\hline AN vol. $\%$ & $\mathbf{V}$ & $\mathbf{V}_{w}$ & $V_{\mathrm{e}}$ & $\mathbf{r}_{0}$ & $\mathbf{V}$ & $\mathbf{V}_{\mathbf{w}}$ & $V_{\mathrm{e}}$ & $\mathbf{r}_{0}$ \\
\hline & \multicolumn{4}{|c|}{ at $293.15 \mathrm{~K}$} & \multicolumn{4}{|c|}{ at $298.15 \mathrm{~K}$} \\
\hline 0 & 412.87 & 272.90 & -140.0 & 4.6246 & 392.22 & 259.26 & -133.0 & 4.5467 \\
\hline 20 & 657.38 & 434.53 & -222.9 & 5.3907 & 651.05 & 430.35 & -220.7 & 5.3759 \\
\hline 40 & 673.20 & 444.98 & -228.2 & 5.4342 & 667.64 & 441.32 & -226.3 & 5.4208 \\
\hline 60 & 717.78 & 474.45 & -243.3 & 5.5463 & 708.40 & 468.26 & -240.1 & 5.5255 \\
\hline 80 & 752.40 & 497.33 & -255.1 & 5.6344 & 744.62 & 492.20 & -252.4 & 5.6189 \\
\hline 100 & 817.14 & 540.13 & -277.0 & 5.7990 & 811.13 & 536.16 & -275.0 & 5.7866 \\
\hline
\end{tabular}

Table 5. Molar volume $(V)$, Van der Waals volume $\left(V_{w}\right)$, electrostriction volume $\left(V_{e}\right)$ and Solvated radii $\left(r_{o}\right)$ of $B D P A$ in different $\left(A N-H_{2} O\right)$ mixed solvents at 303.15K and 308. $\left(\mathrm{Cm}^{3} \cdot \mathrm{mol}^{-1}\right)$.

\begin{tabular}{lllllllll}
\hline AN vol. $\%$ & $\mathbf{V}$ & $\mathbf{V}_{\mathbf{w}}$ & $\mathbf{V}_{\mathbf{e}}$ & $\mathbf{r}_{\mathbf{0}}$ & $\mathbf{V}$ & $\mathbf{V}_{\mathbf{w}}$ & $\mathbf{V}_{\mathbf{e}}$ \\
\hline & at 303.15K & & & & at 308.15K & & \\
\hline 0 & 365.57 & 240.582 & -123.4 & 4.4325 & 343.76 & 227.22 & -116.5 \\
20 & 646.17 & 426.974 & -219 & 5.3425 & 637.01 & 421.06 & -215.9 & \\
40 & 664.46 & 439.206 & -225.3 & 5.40012 & 657.79 & 434.79 & -223 & -3527 \\
60 & 704.32 & 466.296 & -239.1 & 5.5022 & 695.25 & 459.56 & -235.7 & -249 \\
80 & 737.94 & 488.223 & -250.4 & 5.6021 & 734.61 & 485.57 & 5.3396 \\
100 & 799.36 & 527.194 & -270.4 & 5.7321 & 779.37 & 515.16 & -264.2 & 5.4951 \\
\hline
\end{tabular}

It is obvious that the solvated radii of BDPA in $\left(\mathrm{AN}-\mathrm{H}_{2} \mathrm{O}\right)$ mixtures are increased as the organic solvent content increase and as the temperature increase. This may be due to the excess solvation processes, and the higher solvated radii of the organic solvent used than those of water and also to the increasing in the electronic clouds around the solvated molecules as a result of the increase in their vibration and rotation motions with increasing the temperature.

\section{Conclusion}

In this work we calculate ion-ion interaction, dielectric constant, density of organic-aqueous mixtures of ethanol-water solvents, density of saturated solutions of BDPA, salvation volumes (Van der Waals volume $\mathrm{V}_{\mathrm{W}}$, molar volume $\mathrm{V}_{\mathrm{M}}$ and electrostriction volume Ve)and solvated radii from solubility experiments. It was found that values of the $\log \gamma_{ \pm}$of BDPA in $\left(\mathrm{AN}-\mathrm{H}_{2} \mathrm{O}\right)$ mixture were decreases by increasing in the content of the organic solvent used (AN). The values of the log $\gamma_{ \pm}$found to decrease with the increase in temperature. The densities of the saturated solutions of BDPA decrease by increasing ratio of $\mathrm{AN}$ and also increases by increasing in temperature. The values of the molar volume of ethanol mixtures with water are increased by increasing the organic solvents content in the mixtures due to the increase in the volume of organic solvent compared to water. All the electrostriction volumes calculated for BDPA having negative values. The electrostriction volumes increase in negativity on increasing the percentages of the organic solvent. The solvated radii of BDPA are increased as the organic solvent content increase and as the temperature increase.

\section{References}

[1] Fleisher D, Bong R, and Stewart BH (1996) Improved oral drug delivery: solubility limitations overcome by the use of prodrugs. Adv Drug Deliv Rev 19:115-130.

[2] Stella VJ and Nti-Addae KW (2007) Prodrug strategies to overcome poor water solubility. Adv Drug Deliv Rev 59:677694.

[3] Di L, Kerns EH, and Carter GT (2009) Drug-like property concepts in pharmaceutical design. Curr Pharm Des 15:2184 2194.

[4] Keserü GM and Makara GM (2009) The influence of lead discovery strategies on the properties of drug candidates. Nat Rev Drug Discov 8:203-212.

[5] Ishikawa M and Hashimoto Y (2011) Improvement in aqueous solubility in small molecule drug discovery programs by disruption of molecular planarity and symmetry. J Med Chem 54:1539-1554.

[6] Amidon GL, Lennernäs H, Shah VP, and Crison JR (1995) A theoretical basis for a biopharmaceutic drug classification: the correlation of in vitro drug product dissolution and in vivo bioavailability. Pharm Res 12:413-420.

[7] Wu CY and Benet LZ (2005) Predicting drug disposition via application of BCS: transport/absorption/elimination interplay and development of a biopharmaceutics drug disposition classification system. Pharm Res 22:11-23.

[8] Butler JM and Dressman JB (2010) The developability classification system: application of biopharmaceutics concepts to formulation development. J Pharm Sci 99: 4940-4954. 
[9] Chen ML, Amidon GL, Benet LZ, Lennernas H, and Yu LX (2011) The BCS, BDDCS, and regulatory guidances. Pharm Res 28:1774-1778.

[10] Amidon GL, Lennernäs H, Shah VP, and Crison JR (1995) A theoretical basis for a biopharmaceutic drug classification: the correlation of in vitro drug product dissolution and in vivo bioavailability. Pharm Res 12:413-420.

[11] Yu LX, Amidon GL, Polli JE, Zhao H, Mehta MU, Conner DP, Shah VP, Lesko LJ, Chen ML, and Lee VHL, et al. (2002) Biopharmaceutics classification system: the scientific basis for biowaiver extensions. Pharm Res 19:921-925.

[12] Dahan A, Miller JM, and Amidon GL (2009) Prediction of solubility and permeability class membership: provisional BCS classification of the world's top oral drugs. AAPS J 11:740-746.

[13] E. A. Gomaa, E. M. A. Elleef, E. T. Helmy, Conductance Studies on Complex Formation between $\mathrm{CaCl}_{2}$ and Ampicillin as Ligand in Water and in Methanol Solvent at Different Temperatures, RR JPPS, 3 (3), 55-64, (2014).

[14] E. A. Gomaa, E. M. Abouelleef, E. T. Helmy, Complexation of 2-Mercaptoimidazol with some Barium Salts Conductometrically in Various Solvent at Different Temperatures Int. J. Mod. Chem., 7 (2), 141-155, (2015).

[15] E. A. Gomaa, E. M. Abouelleef, E. T. Helmy, Solvent Effects on the Thermodynamics of Solvation of BARIUM DIPHENYLAMINE SULFONATE in Ethanol-Water Mixed Solvents, South. Braz. J. Chem., 21 (21), 31-40 (2013).

[16] E. T. Helmy, E. A. Gomaa, E. M. A. Elleef, A. Negm, Conductometric, Spectrophotometric and in-vivo Investigation of the Interaction of $\mathrm{Ca}$ (II) Ion with Oxytetracycline Hydrochloride, I JPMBS, 4 (3), 197-203, (2015).

[17] E. T. Helmy, E. A. Gomaa, E. M. Abou Eleef. Gibbs Free Energy and Activation Free Energy of Complexation of Some Divalent Cations with Ampicillin in Methanol at Different Temperatures. American Journal of Applied and Industrial Chemistry. 2 (5), 29-32 (2016).

[18] I. A. Sedov, T. I. Magsumov, T. M. Salikov and B. N. Solomonov, Solvation of apolar compounds in protic ionic liquids: the non-synergistic effect of electrostatic interactions and hydrogen bonds, Phys. Chem. Chem. Phys., 2017, 19, 25352 .

[19] Jayanta Kumar Dasha Susmita Kamil, ion solvation in salts of biologically important rare earth metals with aqueous sugar alcohol (sorbitol) mixed-solvent systems, Journal of Taibah University for Science 11 (2017) 801-807.

[20] Virginia Mazzini and Vincent S. J. Craig, What is the fundamental ion-specific series for anions and cations? Ion specificity in standard partial molar volumes of electrolytes and electrostriction in water and non-aqueous solvents, Chem. Sci., 2017, 8, 7052-7065.

[21] M. Aghaie, H. Aghaie, A. Ebrahimi, Thermodynamics of the solubility of barium nitrate in the mixed solvent, ethanol + water, and the related ion-association, J. Mol. Liq. 135, 72, (2007).

[22] M. Aghaie, S. Gafoorian, B. S. Broojeni, H. Aghaie, The effect of dielectric constant and ionic strength on the solubility of lithium carbonate at $25.0^{\circ} \mathrm{C}$ in thermodynamic view, J. Phys. Theor. Chem, 5, 223, (2009).

[23] E. A. Gomaa, Eur. Chem. Bull., Solvation parameters for sodium oxalate in mixed ethanol-water solvents at $301.15 \mathrm{k}, 1$ (5), 254-261. (2013).

[24] A. A. El-khouly, E. A. Gomaa, and S. Abou El-leef, Apparent assocation constants of $\mathrm{HgCl}_{2}$ Association constants from conductivity, (Bulletin of electrochemistry 19 (5), 193-202, (2003).

[25] Acree, W. E., Jr. Thermodynamic Properties of Nonelectrolyte Solutions; Harcourt Brace Javanovich, Publishers: Orlando, (1984).

[26] Padova, J. and Abrahamer, I., Ion-solvent interactions. VII. Apparent and partial molal volumes of some symmetrical tetraalkylammonium halides in anhydrous methanol solutions, J. Phys. Chem., 71, 2112 (1967).

[27] M. Aghaie, S. Gafoorian, B. S. Broojeni, H. Aghaie, The effect of dielectric constant and ionic strength on the solubility of lithium carbonate at $25.0^{\circ} \mathrm{C}$ in thermodynamic view, J. Phys. Theor. Chem, 5 223, (2009). 